\title{
RANCANG BANGUN SISTEM INFORMASI PENJUALAN APARTMENT JATINANGOR CITY PARK
}

\author{
Erna Hikmawati \\ Fakultas Ilmu Komputer Universitas Nasional PASIM \\ Jl. Dakota No.8A Sukaraja Cicendo Bandung 40175 Telepon (022) 6072803 \\ erna.hikma@gmail.com
}

\begin{abstract}
Abstrak
PT. Koryza (Kurnia Oryza Abadi) adalah suatu perusahaan yang bergerak dalam bidang properti beralamatkan di Cibeusi, Jatinangor, Kabupaten Sumedang, Jawa Barat. Pada system yang berjalan PT. Koryza Abadi ini masih menggunakan buku besar, Microsoft Word dan Microsoft Excel dalam mengelola transaksinya, hal ini sangat tidak efektif dan efisien apabila admin pejualan melakukan pencarian data pembeli yang melakukan pembelian unit, transaksi pembayaran cicilan tiap bulan serta mencari data unit yang masih tersedia. Berdasarkan permasalahan diatas, maka dibangun sistem informasi yang diharapkan dapat mempermudah admin penjualan dalam melakukan pendataan dan mencatat transaksi penjualan sehingga dapat lebih efektif dan efisien. Metode pendekatan yang digunakan dalam membangun sistem informasi ini yaitu metode objek oriented, sedangkan bahasa pemograman yang digunakan adalah PHP dengan MySql sebagai databasenya. Sistem informasi yang dibangun dapat mengelola data calon pembeli, data pembeli dan data unit, dapat memberikan notifikasi terhadap tanggal jatuh tempo cicilan pembeli, perengkingan pada staf marketing berdassarkan banyak unit yang terjual dan dapat menampilkan grafik penjualan, omzet yang di dapat beserta jumlah unit yang terjual dan tersedia
\end{abstract}

Kata kunci : Sistem Informasi, Penjualan, Apartment, PHP, MySql

\section{Abstract}

PT. Koryza (KurniaOryzaAbadi) is a company engaged in property in Cibeusi, Jatinangor, Sumedang Regency, West-Java. On the running system, PT. KoryzaAbadi is still using a ledger; Microsoft word and Microsoft excel in the transaction management. It is very ineffective and efficient when sales admin searches customer's data that do a unit transaction, installment per month transaction, and a unit data, which are still available. Based on the problem, it is built an information that is expected to facilitate sales admin in collecting the data and recording sales transaction that can be more effective and efficient. The approach method used in developing this information system is object-oriented method, whereas programming language used is PHP with MySQL as its database. The information system built can manage the data of prospective buyers, buyer data and unit data, and it can provide notification to the buyer's due to date of buyer's repayment, the racketeering to the marketing staff based on many units sold and it can display sales chart, turnover that can be obtained and number of units that are sold and available.

Keywords: Information System, Sales, Apartment, PHP, MySQL. 


\section{PENDAHULUAN}

Pesatnya perkembangan peradaban manusia dewasa ini salah satunya diakibatkan oleh proses pesatnya perkembangan ilmu pengetahuan dan teknologi. Berbicara mengenai suatu hal yang berhubungan dengan perkembangan teknologi itu tak akan ada habisnya. Perkembangan ilmu dan teknologi saat ini juga telah mempengaruhi aktivitas perusahaan dalam mengolah data menjadi informasi.

Perusahaan merupakan satu kesatuan sistem yang saling mempengaruhi untuk satu sama lain agar dapat mencapai sebuah tujuan tertentu. Seiring dengan berkembangnya sebuah perusahaan, adakalanya suatu sistem yang ada pada perusahaan tidak lagi efektif dan efisien dalam menyelesaikan masalah-masalah yang muncul. Seperti penanganan pengolahan data yang semakin meningkat, aturan dalam pengolahan data yang semakin bervariasi dan halhal lain yang dapat digunakan sebagai indikator adanya permasalahan.

Untuk mengatasi permasalahan tersebut, diperlukan suatu sistem yang dapat mendukung operasi yang bersifat manajerial dan kegiatan strategi dari suatu perusahaan demi tercapainya tujuan perusahaan yang dinamakan sistem informasi.

PT. Koryza (Kurnia Oryza Abadi) adalah suatu perusahaan yang bergerak dalam bidang properti. PT. Koryza memang belum memiliki nama di dunia properti khususnya di kawasan Bandung Raya. Namun perusahaan yang baru mulai serius menjalani bidang usaha di bidang properti ini dimiliki oleh KOPELINDO (Koperasi Pegawai Bulog Seluruh Indonesia) yang juga adalah salah satu pemilik saham terbesar Bank Bukopin. PT. Koryza membangun sebuah Apartment yang diberi nama Janati Park. Janati Park adalah singkatan dari Jatinangor City Park, sebuah Apartment yang cukup berhasil dikembangkan developer PT. Koryza di kawasan pendidikan Jatinangor.

Apartment ini pada awalnya menembak pangsa pasar mahasiswa dan orang tuanya yang membutuhkan akomodasi selama sang anak menuntut ilmu di salah satu kampus yang berada di Jatinangor. Dalam perkembangannya, banyak pula pembeli yang sengaja membeli unit di Janati Park untuk digunakan sebagai rumah kost. Peluang pasar itu lah yang kemudian dibidik oleh PT. Koryza dengan menghadirkan Janati Park Apartment.

Ada dua metode penjualan unit di Janati Park Apartment yaitu penjualan secara tunai dan kredit. Pada penjualan tunai pembeli harus melakukan Booking Fee selanjutnya melakukan pembayaran uang muka dan terakhir melakukan pembayaran pelunasan. Sedangkan pada penjualan secara kredit, pembeli harus melakukan Booking Fee, melakukan pembayaran uang muka dan selanjutnya yaitu melakukan pembayaran pembayaran cicilan pada setiap bulannya sesuai ketentuan.

Ada beberapa cara pembayaran utuk pembelian unit di Janati Pak ini, yaitu Cash Keras, KPR, KPR Jaminan Lain, Cash Bertahap dan Baloon Payment. Dalam pencatatan penjualan tunai dan kredit serta pembayaran cicilan merupakan sesuatu yang penting untuk kemajuan perusahaan, namun pada PT. Koryza ini masih menemukan kesulitan dalam mencatat data pembeli yang telah melakukan booking fee, pembayaran uang muka, pembayaran pelunasan, serta kesulitan untuk melihat berapa kali pembeli telah melakukan cicilan.

PT. Koryza yang mempunyai total 884 unit ini masih menggunakan buku besar 
dan Microsoft Excel dalam mengelola transaksinya, hal ini sangat tidak efektif dan efisien apabila petugas pencatat melakukan pencarian data pembeli yang melakukan kredit unit, transaksi pembayaran cicilan tiap bulan serta mencari data unit yang masih tersedia. Persoalan menjadi bertambah karena buku besar secara fisik memerlukan ruangan yang cukup besar untuk menyimpan arsip serta dokumen yang berkaitan dengan penjualan unit. Berikut adalah rincian unit yang tersedia di Janati Park.

Tabel 1.1. Rincian Unit di Jatinangor City Park

\begin{tabular}{|c|c|c|c|}
\hline No & Blok & $\begin{array}{c}\text { Jumlah } \\
\text { Bangunan }\end{array}$ & $\begin{array}{c}\text { Jumlah } \\
\text { Kamar }\end{array}$ \\
\hline 1 & A & 5 & 65 \\
\hline 2 & B & 20 & 260 \\
\hline 3 & C & 13 & 169 \\
\hline 4 & D & 16 & 208 \\
\hline 5 & E & 7 & 91 \\
\hline 6 & F & 7 & 91 \\
\hline
\end{tabular}

Untuk mengatasi permasalahan tersebut, penulis membuat sistem yang dapat digunakan untuk mengolah data penjualan unit pada PT. Koryza. Dengan adanya sistem informasi penjualan unit ini, bagian administrasi dapat dengan mudah melakukan pencarian data penjualan unit yang diperlukan untuk melakukan transaksi pembayaran yang dilakukan pembeli setiap bulan.

\section{METODELOGI PENELITIAN}

Tahapan yang dilakukan dalam penelitian adalah sebagai berikut :

\subsection{Pengumpulan Data}

Untuk memperoleh informasi yang berhubungan dengan penelitian ini, penulis melakukan pengumpulan datadata yang diperlukan untuk melakukan pembangunan system informasi.
Metode pengumpulan data melalui 2 cara,yaitu :

a. Pengambilan data secara langsung (Fields Research)

Untuk pelaksanaan pengambilan data secara langsung ini menggunakan 2 cara yaitu :

1) Observasi Langsung,yaitu mengamati langsung ke lapangan untuk mengetahui bagaimana prosedur pembelian dan pembayaran unit oleh pembeli.

2) Wawancara, yaitu tanya jawab dengan beberapa individu dalam organisasi tersebut yang terlibat langsung dalam penjualan unit Apartmen Janati Park.

b. Studi Literatur (Studi Pustaka)

Selain pengambilan data secara langsung, demi tercapainya tujuan pembangunan aplikasi sehingga memenuhi kriteria pembangunan aplikasi yang baik dan sistematis, maka penyusun juga melakukan studi literatur. Studi literatur ini dimaksudkan penyusun untuk mencocokkan antara fakta yang terjadi dengan aspek-aspek yang ada dalam pembangunan sistem informasi.

\subsection{Model Proses Pembangunan Perangkat Lunak}

Pengembangan sistem menggunakan analisa berorientasi objek dengan model proses prototype. Menurut Pressman (2012), seringkali pelanggan mendifinisikan satu set tujuan umum untuk perangkat lunak, tetapi tidak mengidentifikasi persyaratan rinci untuk fungsi dan fitur. Di lain kasus, pengembang mungkin tidak yakin dari efisiensi dari sebuah algoritma, adaptasi dari sistem operasi, atau bentuk yang interaksi manusia-mesin harus ambil. Dalam hal ini, dan situasi lain, paradigma prototype mungkin menawarkan pendekatan yang terbaik. 
Tahapan-tahapan dalam Prototyping adalah sebagai berikut :

a. Pengumpulan kebutuhan, pelanggan dan developer bersama-sama mendefinisikan format seluruh perangkat lunak, mengidentifikasikan semua kebutuhan, dan garis besar sistem yang akan dibuat.

b. Membangun Prototyping, membangun prototyping dengan membuat perancangan sementara yang berfokus pada penyajian kepada pelanggan (misalnya dengan membuat input dan format output).

c. Evaluasi Protoryping, evaluasi ini dilakukan oleh pelanggan apakah prototyping yang sudah dibangun sudah sesuai dengan keinginan pelanggan. Jika sudah sesuai maka langkah 4 akan diambil. Jika tidak prototyping direvisi dengan mengulangi langkah 1, 2, dan 3 .

d. Mengkodekan sistem, dalam tahap ini prototyping yang sudah disepakati diterjemahkan ke dalam bahasa pemrograman yang sesuai.

e. Menguji sistem, setelah sistem sudah menjadi suatu perangkat lunak yang siap pakai, harus dites dahulu sebelum digunakan. Pengujian ini dilakukan dengan Black Box.

f. Evaluasi sistem, pelanggan mengevaluasi apakah sistem yang sudah jadi telah sesuai dengan yang diharapkan.

g. Menggunakan sistem, perangkat lunak yang telah diuji dan diterima pelanggan siap untuk digunakan.

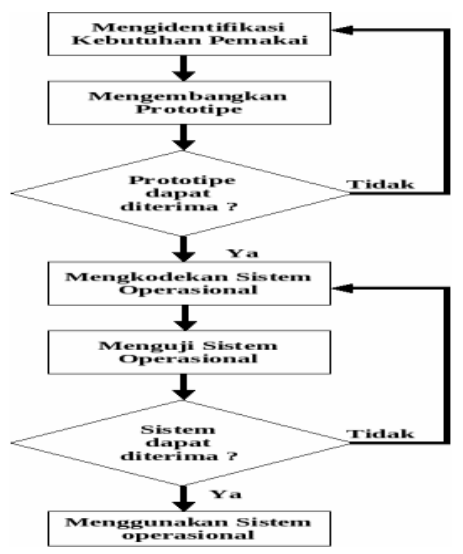

Gambar 2.1 : Tahap-tahap model Prototype

\subsection{Model Pendekatan Sistem}

Metode pendekatan sistem yang digunakan dalam pembangunan sistem informasi ini yaitu Teknik Pembangunan Sistem dengan Metode pendekatan berbasis objek (object oriented method) dan hasil analisis menggunakan UML (Unified Modeling Language).

UML adalah sebuah bahasa yang telah menjadi standar dalam industry untuk visualisasi, merancang dan mendokumentasikan sistem piranti lunak. UML menawarkan sebuah standar untuk merancang model sebuah sistem. Yang biasa diguanakan dalam UML untuk membangun sebuah sistem adalah Use case Diagram, Sequence Diagram, Class Diagram dan Activity Diagram.

\section{HASIL DAN PEMBAHASAN}

Untuk mempermudah perancangan serta pembacaan Use Case, maka Use Case dipisahkan berdasarkan aktor yang terlibat. Berikut ini dijelaskan aktor apa saja yang terlibat :

a. Admin

Hak akses administrator diberikan kepada admin penjualan yang bertugas untuk mengelola sistem secara keseluruhan. Admin penjualan merupakan user utama dalam sistem penjualan ini. Admin mempunyai akses untuk mengelola setiap data antara lain data master (blok, kamar, rumah dan cara pembayaran), data user dan data pembeli. Setiap user (marketing, keuangan, dan General Manager) hanya bisa didaftarkan oleh admin. Admin mempunyai akses untuk melihat setiap report 
yang ada di sistem. Admin mempunyai akses untuk mengelola data transaksi yang masuk sistem.

b. Keuangan

Hak akses keuangan diberikan kepada user yang bertugas untuk mengelola data-data keuangan seperti pembayaran cicilan bulanan pembeli dan cicilan komisi untuk bagian staff marketing dan supervisor. Keuangan mempunyai hak akses melihat laporan penjualan unit, laporan omzet dan cicilan pembeli setiap bulan.

c. Marketing

Hak akses staf marketing diberikan kepada setiap bagian staf marketing untuk menginput data pembeli yang ingin membeli unit di PT. Koryza Abadi, melihat peringkat staf marketing, melihat jumlah komisi, melihat cicilan pemberian komisi, melihat data penjualan unit, omzet yang diperoleh PT. Koryza Abadi.

d. General Manager

General Manager mempunyai hak akses untuk melihat Data pembeli unit, melihat laporan penjualan unit serta omzet yang didapat.

\section{a. Use Case Diagram}

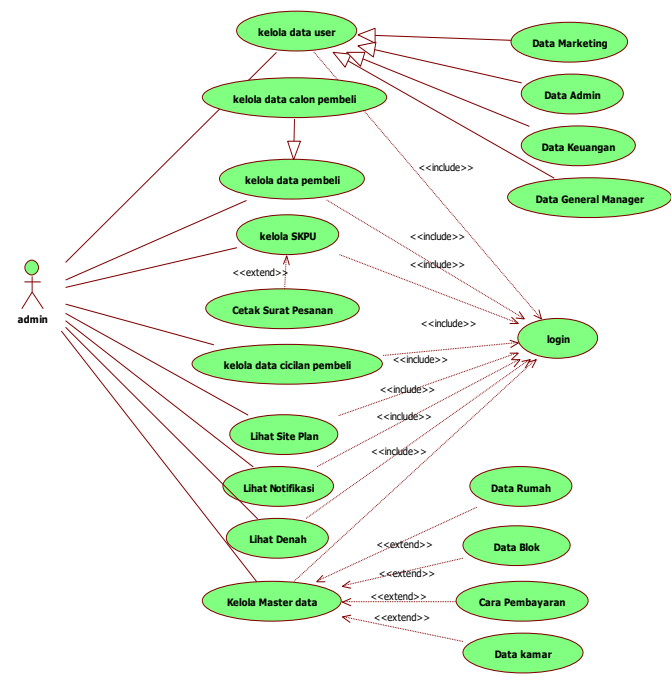

Gambar 3.1 Use Case Admin

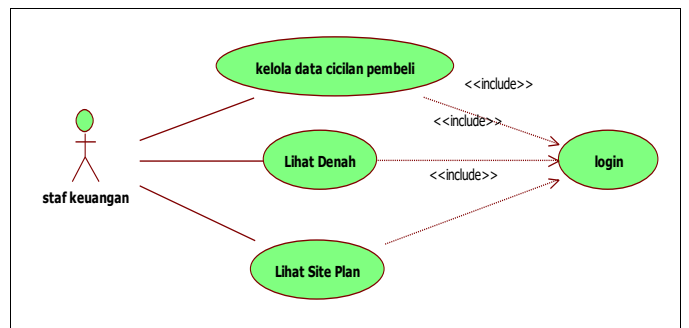

Gambar 3.2 Use Case

Keuangan

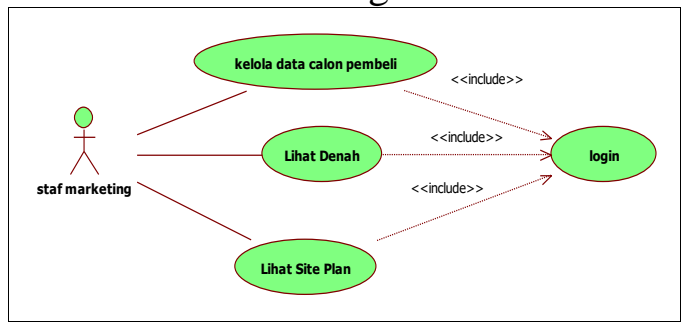

Gambar 3.3 Use Case

Marketing

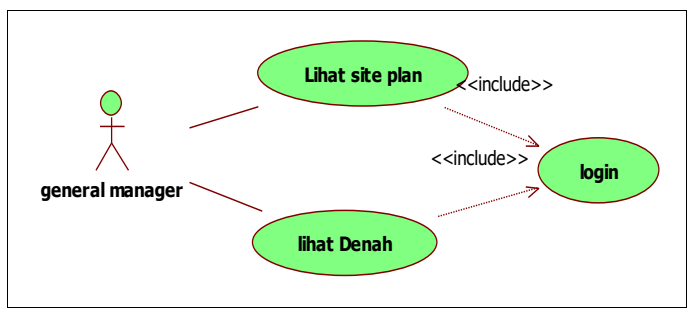

Gambar 3.4 Use Case General Manager

\section{b. Class Diagram}

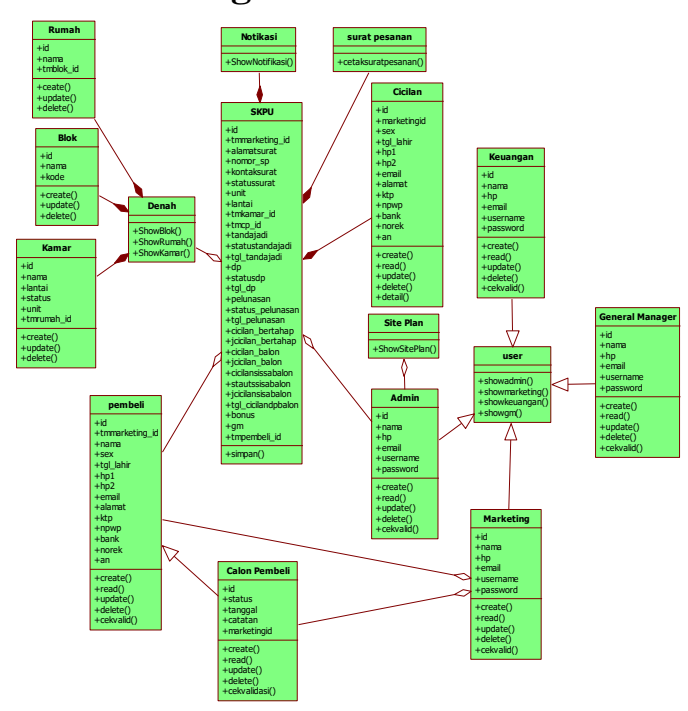

Gambar 3.5 Gambar Class Diagram 


\section{c. Implementasi Antar Muka \\ 1. Tampilan Login}

Berikut ini merupakan tampilan login dari sistem informasi penjualan apartment :

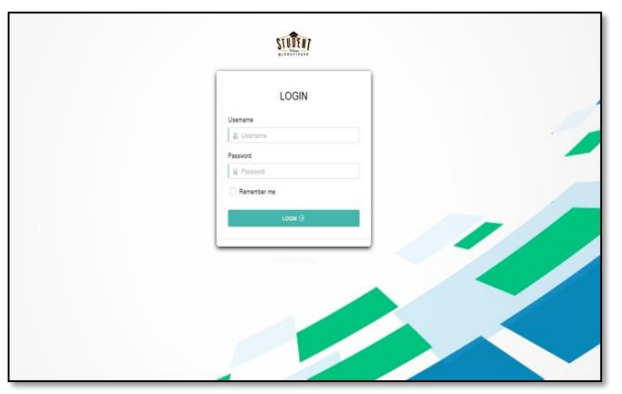

Gambar 3.5 Tampilan utama

\section{Tampilan Utama}

Berikut ini tampilan menu utama semua user sama yang membedakan ialah menu yang dimiliki setiap user berbeda.

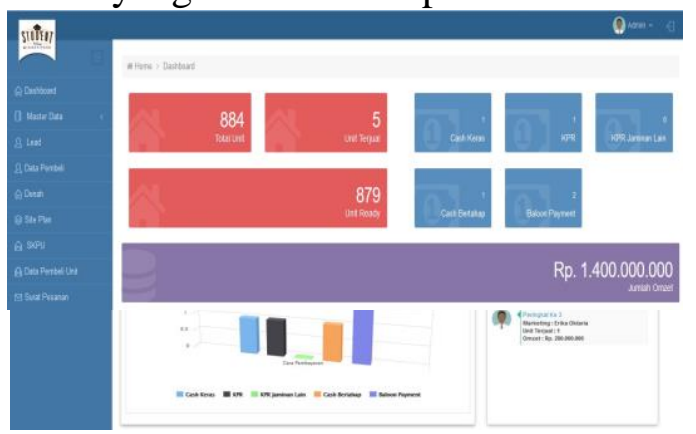

Gambar 3.6 Tampilan utama Admin

\section{Lihat Denah}

Menu lihat denah ini berlaku untuk semua user. Proses ini dimulai dengan mengklik menu Denah. Berikut ini tampilan utama dari menu denah :

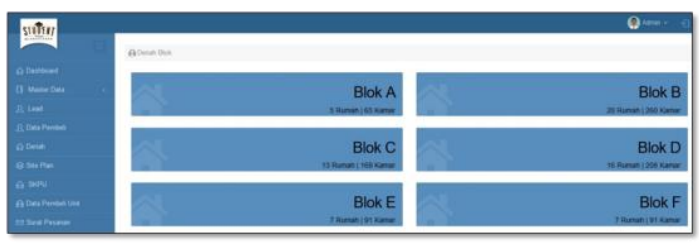

Gambar 3.7 Tampilan Denah

\section{Lihat Site Plan}

Menu lihat Site Plan ini berlaku untuk semua user. Proses ini dimulai dengan mengklik menu Site Plan. Berikut ini tampilan utama dari menu Site Plan:

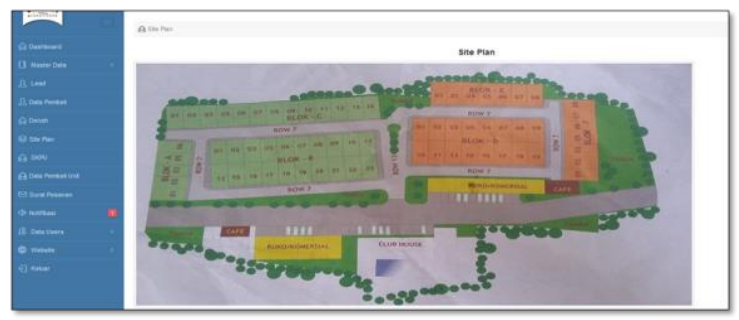

Gambar 3.8 Tampilan Site Plan

\section{KESIMPULAN}

Dari hasil analisis dan perancangan serta implementasi Sistem Informasi Sistem Informasi Penjualan Apartment Jatinangor City Park maka dapat disimpulkan beberapa poin sebagai berikut :

1. Dengan dibangunnya sistem informasi penjualan apartment dapat mengelola data calon pembeli, data pembeli dan data unit.

2. Sistem informasi dapat memberikan notifikasi terhadap tanggal jatuh tempo cicilan pembeli.

3. Sistem informasi dapat melakukan perengkingan pada staf marketing berdassarkan banyak unit yang terjual.

4. Penyimpanan data selama proses pencatatan data unit, data pembeli maupun data cicilan lebih terorganisir karena menggunakan penyimpanan basis data yang terkomputerisasi.

5. Sistem informasi dapat menampilkan grafik penjualan, omzet yang di dapat beserta jumlah unit yang terjual dan tersedia.

\section{SARAN}

Untuk pengembangan Sistem Informasi Penjualan Apartment ini penulis memiliki beberapa saran sebagai berikut : 
1. Dengan semakin berkembangnya teknologi, disarankan agar kedepannya sistem informasi ini dalam memberikan notifikasi pembayaran, bukan hanya untuk admin penjualan, melainkan dapat terhubung ke nomor ataupun email pembeli.

\section{DAFTAR PUSTAKA}

Al Fatta, Hanif. 2007. Analisis dan Perancangan Sistem Informasi. Yogyakarta.

\section{Andi}

Alexander F.K. Sibero. 2011. Kitab Suci Web Programing. Yogyakarta : Mediakom

Bambang Hariyanto. 2004. Sistem Manajemen Basis Data (Pemodelan Perancangan dan Terapannya).

Bandung : Informatika

Connolly, Thomas \& Begg, Carolyn. 2002. Database System : A Practical Approach to Design, Implementation and Management. Third Edition. England : Addision Wesley

Edhy Sutanto.2004. Sistem Basis Data. Yogyakarta: Andi Offset.

Jugiyanto.(2005) Komponen Sistem Informasi. Yogyakarta: Andi

Kadir, Abdul. 2003. Pengenalan Sistem Informasi. Yogyakarta : Andi

Kadir, Abdul. 2004. Dasar Pemograman WEB Dinamis Mengguakan PHP. Yogyakarta : Andi

Ladjamudin, bin Al Bahra. 2005. Analisis dan Sistem Informasi. Yogyakarta :
2. Disarankan agar menambahkan fitur berbasis yang diperuntukan bagi calon pembeli maupun pembeli agar lebih mudah dalam melakukan pembelian maupun pengecekan pembayaran cicilan.

Graha Ilmu

Lynch, Kevin and Hack, Gary. 1984. Site Planing. MIT Press. London : Cambridge

MA

Mulyanto, Agus. 2009. Sistem Informasi Konsep dan Aplikasi.

Yogyakarta :

Pustaka Pelajar.

Nugroho, Adi. 2010. Rekayasa

Perangkat Lunak Berbasis Objek dengan Metode

USDP. Yogyakarta : Andi

Pressman, Roger S .2002. Rekayasa

Perangkat Lunak (Pendekatan Praktisi)

Buku 1. Yogyakarta : Andi

Pressman, Roger S .2012. Rekayasa Perangkat Lunak (Pendekatan Praktisi) Edisi 7 : Buku 1. Yogyakarta :

Andi

Stair, M. Ralph, George W. Reynolds. 2010. Principles of Information Systems $\therefore A$

Managerial Approach (9 th Edition) : Australia : Thomson Corse Technology

Sutabri, Tata. 2005. Sistem Informasi Manajemen. Yogyakarta : Andi

Whitten, Jeffery L et al. 2004. System Analysis and Design Methds. New York

Mc. Graw Hill 